\title{
Acute coronary syndrome in women
}

\section{Jozica Šikić ${ }^{1,2 *}$, Dario Gulin ${ }^{1,2}$}

'University Hospital "Sveti Duh", Zagreb, Croatia

2University of Zagreb School of Medicine, Zagreb, Croatia
RECEIVED:

January 30, 2018

ACCEPTED:

February 10, 2018

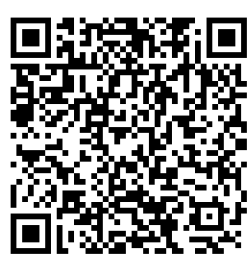

KEYWORDS: acute coronary syndrome, myocardial infarction, women.

CITATION: Cardiol Croat. 2018;13(1-2):35. I https://doi.org/10.15836/ccar2018.35

*ADDRESS FOR CORRESPONDENCE: Josica Šikić, Klinička bolnica "Sveti Duh", Sveti Duh 64, HR-10000 Zagreb, Croatia. / Phone: +385-91-3713-023 / E-mail: josicas1@gmail.com

ORCID: Jozica Šikić, https://orcid.org/0000-0003-4488-0559 • Dario Gulin, https://orcid.org/0000-0001-8502-7816

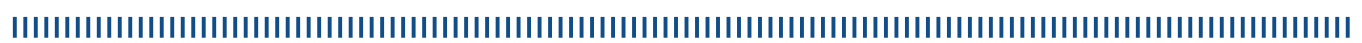

In the last 30 years women have a worse outcome after acute coronary syndrome (ACS) than men, but unfortunately women are not well represented in the studies. Women with ACS are "older and sicker" and are on average about 10 years older than men for the 1st ACS. Younger women with ACS ( $<55$ years) have more comorbidity (diabetes, heart failure, stroke, peripheral artery disease, chronic obstructive pulmonary disease), differences in comorbidities are decreasing with age. Women with diabetes have a 4.3x higher risk for myocardial infarction (MI) than women without diabetes. In men, the risk is $2.7 \mathrm{x}$ higher. Smoking increases the risk for MI 3.3x in women and by $1.9 \mathrm{x}$ in men. In women, under the age of 45 , the difference is more pronounced $(7.1: 2.3)$. Women have smaller coronary artery lumen. Plaque characteristics are different (smaller necrotic nucleus, less calcium) and more frequently endothelial dysfunction, vasospasm due transitional sympathetic-vagal imbalance, plaque erosion and spontaneous coronary artery dissection. Non-obstructive coronary disease (microvascular disease) is more often in women, $10 \%$ women with ACS have not the pathological substrate. Women have more frequent periprocedural complications (mortality, major adverse cardiac events, need for blood derivatives, stroke) higher mortality risk after acute MI and 22\% higher risk for rehospitalization within 30 days. After ST-segment elevation MI they have a worse 30-day outcome than the man. Reasons for later appearing in the late hospitalization, higher comorbidities rate, small coronary vessels, restenosis, "in-stent" thrombosis and distal embolization. Women have a lower troponin level (including hsTn) than men (a lower myocardial mass) and a smaller implementation of new drug eluting stents after the onset of the market. Optimal medical therapy has the same efficacy in women and men, but women are rarely treated with aspirin, GP IIb/IIIa inhibitors and beta blockers. They have a better response to statins in terms of atheroma reduction. They are less referred to cardiologic rehabilitation and less frequently remain on it. Education of women in the term of ACS is essential with the aim to prevent it and reduce risk factors especially diabetes and smoking. ${ }^{1-3}$

LITERATURE IIIIIIIIIIIIIIIIIIIIIIIIIIIIIIIIIIIIIIIIIIIIIIIIIIIIIIIIIIIIIIIIIIIIIIIIIIIIIIIIIIIIIIIIIIIIIIIIIIIIIIIIIIIII

1. Davis M, Diamond J, Montgomery D, Krishnan S, Eagle K, Jackson E. Acute coronary syndrome in young women under 55 years of age: clinical characteristics, treatment, and outcomes. Clin Res Cardiol. 2015 Aug;104(8):648-55. https://doi.org/10.1007/s00392-015-0827-2

2. Daniels LB, Maisel AS. Cardiovascular biomarkers and sex: the case for women. Nat Rev Cardiol. 2015 0ct;12(10):588-96. https://doi.org/10.1038/nrcardio.2015.105

3. White SJ, Newby AC, Johnson TW. Endothelial erosion of plaques as a substrate for coronary thrombosis. Thromb Haemost. 2016 Mar;115(3):509-19. https://doi.org/10.1160/TH15-09-0765 